\title{
Joint evaluation of marketing authorization files of inactivated polio vaccines in countries of the Eastern Mediterranean Region
}

Houda Langar, ${ }^{1}$ Razieh Ostad Ali Dehaghi ${ }^{2}$ and Nora Dellepiane ${ }^{3}$

${ }^{1}$ Regional Advisor, Vaccines Regulation and Production, Department of Health Systems Development, World Health Organization, Regional Office for the Eastern Mediterranean, Cairo, Egypt. ${ }^{2}$ Regulatory Systems Strengthening Team, World Health Organization, Geneva, Switzerland. ${ }^{3} \mathrm{QRB}$ Consultants Sàrl, Switzerland (Correspondence to: Nora Dellepiane: dellepianen@outlook.com).

\begin{abstract}
Background: In 2012, the World Health Assembly declared ending polio a "programmatic emergency for global public health". In response, the Global Polio Eradication Initiative developed "The Polio Eradication and Endgame Strategic Plan 2013-2018" to address the eradication of all types of poliomyelitis.

Aims: The World Health Organization invited selected countries in the Eastern Mediterranean Region to take part in a joint evaluation of the marketing authorization files of candidate standalone inactivated poliovirus vaccines (IPVs), aimed to facilitate the evaluation process and expedite the timelines for registration.

Methods: This report describes the planning, organization and execution of the joint meeting among 6 countries of Eastern Mediterranean Region.

Results: Participants prepared a joint list of questions and concerns which was shared and discussed with the respective manufacturers on the last day of the review. Manufacturer provided answers to the questions. The questions that could not be responded to immediately by the manufacturer remained to be addressed after the meeting directly between the manufacturer and the national regulatory authoritys. A final joint evaluation report was prepared before the end of the meeting by the participating countries.

Conclusions: The report focuses on the benefits of the exercise and highlights its shortcomings as a sole strategy to secure the timely registration of the vaccine in target countries. We discuss additional aspects to be addressed to effectively accelerate registration, and hence access to priority vaccines.
\end{abstract}

Keywords: poliomyelitis, inactivated vaccines, marketing authorization, Eastern Mediterranean

Citation: Langar H; Dehaghi R; Dellepiane N. Joint evaluation of marketing authorization files of inactivated polio vaccines in countries of the Eastern Mediterranean Region. East Mediterr Health J. 2018;24(6):588-594. https://doi.org/10.26719/2018.24.6.588

Received: 30/08/16; accepted: 29/05/17

Copyright (C) World Health Organization (WHO) 2018. Some rights reserved. This work is available under the CC BY-NC-SA 3.0 IGO license (https:// creativecommons.org/licenses/by-nc-sa/3.o/igo).

\section{Introduction}

On 26 May 2012, the World Health Assembly declared ending polio a "programmatic emergency for global public health". In response to this declaration, the Global Polio Eradication Initiative developed "The Polio Eradication and Endgame Strategic Plan 2013-2018". This plan addresses the eradication of poliomyelitis, whether caused by wild poliovirus or circulating vaccine-derived poliovirus (cVDPV). It includes the sequential removal of Sabin poliovirus strains from trivalent oral polio vaccine (tOPV) starting with Sabin type 2. The type 2 poliovirus has been prioritized for removal because wild virus type 2 had been eradicated in 1999 and Sabin type 2 is currently the cause of the majority of vaccine-related paralytic cases. In addition, given the potential of Sabin viruses to mutate and assume the characteristics of wild poliovirus, all live polioviruses will have to be removed from human populations (1-3).

The withdrawal of the type 2 tOPV from routine immunization programmes in all countries, preceded by the introduction of at least 1 dose of inactivated poliovirus vaccine has been endorsed by the Strategic Advisory
Group of Experts on Immunization, the main technical oversight committee of the World Health Organization (WHO) on vaccination (2).

The introduction of 1 dose of IPV into the routine immunization schedule administered concomitantly with the second or third dose of diphtheria, tetanus and pertussis (DTP)-containing vaccines; should take place at least 6 months before the introduction of bivalent OPV (bOPV) planned in April 2016. Immunization with OPV alone for the prevention of poliomyelitis no is longer recommended by $\mathrm{WHO}$ (4).

The registration of standalone IPV became a high priority for national immunization programmes. All countries where a registration was needed, were requested through a joint letter by the Director-General of the WHO, the Executive Director of UNICEF and the Chief Executive Officer of Gavi, the Vaccine Alliance, addressed to the ministers of health to assign it a high priority. In order to enable the smooth introduction of IPV and use of bOPV, the appropriate IPV presentations should have ideally been registered by the end of 2014 and bOPV by the end of 2015 at the latest. 
The WHO recommends that countries importing vaccines that are prequalified by WHO and are supplied through United Nations (UN) procuring agencies grant a marketing authorization to such products. The process followed to grant the marketing authorization may rely on the marketing authorization granted by the national regulatory authority (NRA) in the producing country and/or on the WHO prequalification $(5,6)$.

There are several IPVs and bOPVs from different producers prequalified by WHO. These products have been registered in the country of origin by a "functional" NRA in accordance with assessment performed using WHO established indicators $(7,8)$, and have subsequently undergone an extensive review by the WHO prequalification programme. This prequalification programme provides an independent opinion on the quality, safety and efficacy of vaccines supplied by UN agencies; ensures the efficacy in the target population, including in co-administration with other vaccines used by national immunization programmes; and assesses the programmatic suitability of the vaccine (9-11). In this context, WHO sent communications to the NRAs of countries worldwide requesting them to consider relying on the evaluations performed by the producing country NRA and that performed by the WHO prequalification (through access to their evaluation reports) in order to save resources and time in the process of granting a marketing authorization/ registration of these prequalified products.

Therefore, WHO invited countries in the Eastern Mediterranean Region to take part in a joint evaluation of the files of standalone IPVs for approval for marketing authorization. The meeting was aimed at assisting countries with the review/evaluation of IPV marketing authorization files and hence to facilitate the overall timelines required for granting the marketing authorization, so that the process would be completed by the end of 2014 in all countries of the Region. It was also intended to foster collaboration and exchange of technical information between countries in the Region.

\section{Preparations and conduct of the meeting}

The global production capacity of IPV is insufficient to secure simultaneous introduction of 1 dose of IPV in all countries of the world. Therefore, the polio global eradication initiative established prioritization criteria for the introduction of IPV and grouped countries in tiers as described below and shown in Table 1.

- Tier 1: Wild polio virus (WPV) endemic countries or countries that have reported a circulating vaccine-derived poliovirus type 2 (cVDPV2) since 2000.

- Tier 2: Countries that have reported a circulating vaccine-derived poliovirus type 1 or type 3 (cVDPV1/ cVDPV3) since 2000 or large/medium sized countries with 3 doses of diphtheria, tetanus, pertussis vaccine (DTP3) coverage $<80 \%$ in 2011, 2012 and 2013.
- Tier 3: Large/medium countries adjacent to Tier 1 countries that have reported wild polio virus since 2003, or bordering countries with a current persistent cVDPV2 outbreak (if not already in Tier 1/Tier 2) or countries that experienced a wild polio virus importation since 2011.

- Tier 4: All other OPV-only using countries.

For the countries which had already introduced IPV in their national immunization programmes, the tier concept was not applicable (no tier). Tier 1 countries were assigned the highest priority and Tier 4 countries the lowest.

Countries were also grouped into 3 main categories or regulatory tracks based on the regulatory pathway that they follow for medicines registration, including vaccines:

- Countries that conduct a full evaluation process independently of whether the vaccine is prequalified or not. This pathway implies a complete review of the manufacturer's dossier for quality, safety and efficacy, review of samples (sometimes also testing) and inspection of manufacturing sites for approval and granting of the marketing authorization.

- Countries that follow a facilitated evaluation procedure based on the fact that the vaccine is prequalified. This pathway implies that the NRA may use a facilitated review procedure based on reliance on the review done by the WHO prequalification programme in order to save resources and avoid duplication of work $(12,13)$.

- Countries that accept using a prequalified vaccine based on the prequalification status without any additional review ( $P Q$ vaccine).

A few countries in the Region have provisions applicable to special situations (special approval, acceptance of marketing authorization granted in the United States of America or the European Union) (Table 1). All countries in all regions of the world were contacted to report to WHO whether they had one or more IPV vaccines registered and whether they had provisions to allow the use of alternative regulatory pathways to accelerate registration of IPV. Between $75 \%$ and $80 \%$ of countries answered the request. Countries that did not provide information on status of registration of IPV and/ or pathway applied were not contacted further.

Countries worldwide were mapped according to their tier and regulatory pathway followed, and from this matrix, those that had not registered any standalone IPV or had only 1 brand of IPV registered were selected for this joint evaluation meeting.

Seven countries were identified in the Eastern Mediterranean Region with no IPV or only 1 brand of IPV registered, all of which reported to follow regulatory track 1 for registration of IPV. These were Egypt, Islamic Republic of Iran, Jordan, Morocco, Pakistan, Saudi Arabia and Tunisia. (Saudi Arabia was selected as representing all other Gulf Cooperation Council countries). These countries were offered the opportunity to participate in 
Table 1 Inactivated poliovirus vaccine (IPV) licencing status in countries in the Eastern Mediterranean Region by October 2014

\begin{tabular}{|c|c|c|c|c|c|c|}
\hline Country & Tier & $\begin{array}{l}\text { Immunization } \\
\text { schedule }\end{array}$ & Regulatory pathway & Mfg A & Mfg B & $\begin{array}{l}\text { Standalone } \\
\text { IPV }\end{array}$ \\
\hline Bahrain & No tier & Sequential & No information available & NA & NA & NA \\
\hline Jordan & No tier & Sequential & Full registration & 1 & 0 & 1 \\
\hline Kuwait & No tier & Sequential & $\begin{array}{l}\text { Special approval for emergency } \\
\text { situations }\end{array}$ & 1 & 0 & 1 \\
\hline Lebanon & No tier & Sequential & Full registration & NA & NA & NA \\
\hline Oman & No tier & Sequential & $\begin{array}{l}\text { Special approval for emergency } \\
\text { situations }\end{array}$ & 0 & 0 & 0 \\
\hline Qatar & No tier & Sequential & Full registration & NA & NA & NA \\
\hline Saudi Arabia & No tier & Sequential & Full registration & 1 & 0 & 1 \\
\hline Syrian Arab Republic & No tier & Sequential & Full registration & 1 & 0 & 1 \\
\hline United Arab Emirates & No tier & Sequential & Full registration & 1 & 0 & 1 \\
\hline Libya & 4 & IPV & $\begin{array}{l}\text { Vaccines registered by USFDA or } \\
\text { EU can be used in country }\end{array}$ & 1 & 0 & 1 \\
\hline Afghanistan & 1 & OPV & PQ_vaccine & NA & NA & NA \\
\hline Pakistan & 1 & OPV & Full registration & 1 & 0 & 1 \\
\hline Somalia & 1 & OPV & PQ_vaccine & NA & NA & NA \\
\hline Yemen & 1 & OPV & PQ_vaccine & NA & NA & NA \\
\hline Iraq & 2 & OPV & PQ_vaccine & NA & NA & NA \\
\hline Egypt & 3 & OPV & Full registration & 1 & 0 & 1 \\
\hline Sudan & 3 & OPV & Expedited review procedure & NA & NA & NA \\
\hline Iran (Islamic Republic of) & 3 & OPV & Full registration & 1 & 0 & 1 \\
\hline Djibouti & 4 & OPV & PQ_vaccine & NA & NA & NA \\
\hline Morocco & 4 & OPV & Full registration & 0 & 0 & 0 \\
\hline Tunisia & 4 & OPV & Full registration & 0 & 0 & 0 \\
\hline
\end{tabular}

Mfg = manufacturer.

Sequential = sequential immunization, first with OPV followed by 1 dose of IPV

$N A=$ not available.

USFDA = United States of America Food and Drug Administration.

$E U=$ European Union.

$\mathrm{OPV}=$ oral polio vaccine.

$P Q=$ prequalified vaccine.

a WHO-organized meeting for the joint evaluation of the marketing authorization files from 2 IPV manufacturers (manufacturers A and B). Three communications were sent to the heads of national regulatory agencies to inform them about the polio endgame strategy and about the proposal for facilitated evaluation of the products. A first letter signed by the heads of UNICEF, Gavi, the Vaccine Alliance, and WHO was sent in 2013 to the ministers of health of countries worldwide, an information note issued by WHO on 16 April 2014 by the Assistant Director-General, Health Systems and Innovation, and the Assistant Director-General, Polio and Emergencies was sent to the heads of the national regulatory agencies in target countries worldwide. A third letter from WHO, signed by the Coordinator of the Regulatory Systems Strengthening team was sent to the heads of national regulatory agencies in the 7 target countries in the Eastern Mediterranean Region providing background information on the polio endgame strategy, terms of reference for participation in the joint evaluation meeting, declaration of interests and confidentiality agreements.

The terms of reference described the roles and responsibilities of each of the parties involved, i.e. the NRA, the manufacturers and WHO. Commitments by manufacturers included the timely submission of the marketing authorization files to the NRAs that would participate in the meeting. The NRAs in turn committed to using the joint evaluation reports as the basis for approval of the vaccines by the end of 2014, and WHO committed to organizing the meeting and to following up until completion of the objective.

Six countries responded to the invitation letters, agreed to the terms of reference and signed the confidentiality agreements and the declaration of interests. All, with the exception of Pakistan took part in the meeting.

The confidentiality agreement signed by nominated participants was valid for interactions during and after the review. In addition, the participants confirmed that they had the authority to protect non-public information, including confidential commercial information, provided to them during the meeting and that they would take all practicable steps to protect such non-public information from disclosure unless authorized by the owner in writing. 
The joint review meeting was conducted in Morocco in October 2014 to facilitate the registration of 2 IPV products (from manufacturers A and B) with support from NRAs from the producing countries. The meeting lasted 5 days in total, with two and a half days dedicated to review each product file and other relevant documents.

Six countries participated in the joint evaluation. Countries which did not have any IPV registered took part in the evaluation of both products (Jordan and Morocco), while those in which only 1 of the products was already registered took part in only 1 of the 2 joint product evaluations performed (Egypt, Islamic Republic of Iran, Saudi Arabia and Tunisia).

This joint evaluation meeting was limited to marketing authorization applications of inactivated poliovirus vaccines submitted to the NRAs of countries where the joint evaluation process would be legally accepted for issuance of a marketing authorization. The approval of the IPV vaccines would be based on the information shared during the joint evaluation meeting and the information provided in the assessment reports from the vaccine-producing country NRAs (for the dossier, good manufacturing practice (GMP) inspections and test results). No further testing or inspections would be conducted by the countries before granting the marketing authorization. However, the decision whether or not to register the candidate vaccines remained the prerogative and responsibility of each of the participating authorities.

Participants received the applications and the marketing authorization dossiers in common technical document format, except for additional specific locally required information (e.g. labelling). Three countries, Egypt, Islamic Republic of Iran and Saudi Arabia did not receive the files from manufacturer $B$ through the official channel in time. The participants who received the files within the expected timeframe (1 month before the meeting) reviewed them in advance and shared their findings, questions and concerns during the joint evaluation process. Those who did not receive them in advance through the official submission channels received a copy of the files from WHO with permission from the manufacturers. These were used to advance the review process and facilitate participation in the meeting discussions, but did not represent an official submission, which had to be provided after the meeting.

The meeting brought together representatives from the participating NRAs in the Eastern Mediterranean Region, representatives from the vaccine-producing countries' NRAs, a consultant from the Medicines Control Council of South Africa invited to assist the regulators, and representatives from WHO secretariat as organizers and facilitators.

All the information reviewed and questions raised were reflected in a report produced by the meeting participants, "the joint evaluation report". This common report was presented to representatives of the 2 manufacturing companies. A face-to-face meeting was held with manufacturer A on the last day of the review of their file and a teleconference discussion was held with manufacturer B on the last day of the joint evaluation of their file.

The participants agreed that the timeline for sending the joint evaluation report containing the list of questions to the manufacturers (applicants) would not exceed 2 weeks after the joint evaluation meeting. Official responses from the manufacturers were to be provided within 2 weeks of receipt of the report, and the final decision for marketing authorization would be taken before the end of 2014. The participants decided that in order to perform the oversight of newly introduced IPV vaccines, the sharing of information between the participating NRAs might extend beyond the granting of a marketing authorization to include collaboration for post-marketing monitoring of changes and product performance.

The type of information shared under a confidentiality agreement between participating NRAs, facilitators from the NRAs in the vaccine-producing countries, WHO, and the manufacturers included:

- full dossiers from both companies for the 10-dose presentation of manufacturer $A$ and the 1- and 5-dose presentations from manufacturer $\mathrm{B}$ of standalone IPV and additional information required for approval of the variation for the 5-dose presentation of manufacturer B;

- information contained in the marketing authorization applications and applications to vary a marketing authorization received by any participants which could be of interest to the other participants;

- test results shared by the NRAs of the producing countries;

- assessment reports made by the participants and presentations made during the meeting;

- the final list of questions resulting from the review by all participants;

- post-marketing surveillance data of significant public health interest to other participants;

- outcome of GMP inspections conducted by the NRAs of the 2 manufacturing countries;

- the manufacturers' immediate responses to questions.

\section{Results}

The representative from the NRA from vaccine-producing country A presented a summary of the production process and quality control, the assessment report of the quality part of the common technical document, and the lot release and test results reports of the previous 3 years. The GMP reports were discussed via teleconference by the GMP inspectors who had conducted the inspections on behalf of the NRAs of the manufacturing country (producing country NRAs). The review of the non-clinical, clinical and post-marketing surveillance data was 
presented by the expert consultant from South Africa. Each participating country made a presentation of their independent review performed ahead of the meeting and provided their main findings and observations and points for further clarification.

After review of each part, participants prepared the joint list of questions and concerns which was shared and discussed with the respective manufacturers on the last day of the review. Each manufacturer provided as many answers to the questions as possible. The questions that could not be responded to immediately by the manufacturer remained to be addressed after the meeting directly between the manufacturer and the NRAs. A final joint evaluation report was prepared before the end of the meeting by the participating countries.

The second half of the week was dedicated to the product of manufacturer B. A similar process as that applied to manufacturer A was followed.

Countries followed up with manufacturers after the meeting on a bilateral basis with respect to the official path for submissions, the responses to pending questions, issue of final reports and granting of marketing authorization.

Post-meeting information gathered by WHO from the participating countries shows that the approval of the IPV vaccines subject to the joint review in the relevant countries of the Eastern Mediterranean Region has been achieved as shown below.

- Egypt registered product B in 2015.

- Jordan and Morocco registered product A in the first quarter of 2015 while the approval of product B was delayed until there was full compliance with the information required in module 1.

- Tunisia provided a special approval to product B in 2014 based on emergency provisions.

- Saudi Arabia dropped the registration of product B since they prefer to use product A, which is available in combination.

- The Islamic Republic of Iran registered product B in the first quarter of 2015.

\section{Discussion}

The organization of this joint review meeting for licensure of IPV was communicated 8 months in advance to ministries of health and heads of NRAs in each of the countries, with regular follow-up communications thereafter until the meeting took place in October 2014. Responses from countries were required in order to proceed with sharing the terms of reference: NRAs had to agree and accept the terms of reference in order to be invited to participate in the joint review. The terms of reference indicated clearly the need to use the reports produced during the review as the basis for licensure without further requirements. Participants in the meeting were the scientific reviewers from each of the countries, however they had not been appropriately briefed on the objectives and expected outcomes of the exercise nor on the com- mitments taken by their heads of agencies to secure participation. Despite the thorough and systematic process being followed, the information did not cascade from management in the national regulatory agencies to the technical staff that participated in the meeting.

Manufacturers agreed to submit the same files at least 1 month before the meeting to all participating countries so that reviewers in the countries would have time to go through the data before the meeting. This condition was not met in all cases and participants from 3 countries (Egypt, Islamic Republic of Iran and Saudi Arabia) received advanced copies of the files from manufacturer B through WHO with permission from manufacturers so that they would still have the opportunity to review the files prior to the meeting despite not having received the official submission. However, the submission by the manufacturers through the regular channels (i.e. their respective local agents) remained the requirement to officially start the registration process.

The experience from this joint evaluation showed that the technical staff participating in the meeting, appreciated and benefited from the information and guidance received from the producing country NRAs. In addition to the observations and questions raised by the 6 participating countries from the Eastern Mediterranean Region, the inputs from regulators from the NRAs in the producing countries enriched the discussion. Their presence at the meeting and the sharing with participating NRAs of their assessment reports, test results and GMP inspection reports helped to address GMP related and other questions that would have normally taken time to be addressed to the satisfaction of the NRAs. Participation of manufacturers in the meeting was very useful and accelerated the process of addressing the questions and concerns expressed by participating NRAs. In this particular instance, the evaluation process was different from the regular full review pathway in that duplication of inspections and unnecessary testing at the time of registration of the vaccine were avoided. However, the dossier was reviewed in full by all participating countries with additional support provided by the NRAs in the manufacturing countries. The meeting achieved the overall objective of avoiding duplication of inspections and testing of samples, and thus helped in shortening the timeframes for registration. Furthermore, many of the questions raised in the joint report were immediately addressed by the manufacturers, thus reducing the number of pending items to a minimum.

Besides these achievements, which are not minor, the meeting also helped to identify aspects that remain to be addressed. One important issue is the diversity of country-specific requirements in terms of content, language and format. Although the common technical document dossier was specifically designed to harmonize requirements between regulators worldwide, Module 1, which contains the administrative and legal information, is not harmonized and is subject to a diversity of formats with variable content, including different legal documents in different languages sometimes required to 
be notarized, and mock-up labels and inserts with specific country requirements, including translation to the local language. Such heterogeneity in format and contents of module 1 of the common technical document dossier has to be tackled by manufacturers on a country-by-country basis and takes significant resources and time.

Another aspect highlighted during the organization of the meeting was that internal communication within the NRAs was not equal to the needs and failed to cascade the information from the heads of the NRAs to the scientific staff that participated in the meeting.

Furthermore, the majority of NRAs across the world require manufacturers to establish in their respective country a national agent who is responsible of all communications between the NRA and the manufacturer. These national agents are responsible for submitting the application forms, as well as the files and providing responses to questions, and translations to the local language if needed, etc. It is not easy for manufacturers to find adequate, responsive agents in many countries. In the specific case of this joint review meeting, lack of responsiveness from some of the agents and difficulties in complying with the specific country requirements of Module 1 delayed some of the submissions beyond the proposed timeframes.

In recent years, WHO has organized several joint review meetings to assist countries with either the scientific review of clinical trial applications or the review of marketing authorization dossiers for different vaccines. The joint reviews conducted in the context of licensure of MenAfriVac in countries of the meningitis belt in Africa is just 1 example of such activities (12). These activities have provided the opportunity for countries to further strengthen their technical understanding of the products and the quality, pre-clinical and clinical issues to be considered, depending on the vaccine type and epidemiology of the disease. Joint evaluations also contribute to building trust and fostering collaboration between regulators, opening the door to networking and to mutual reliance. As relevant as these activities may be, they are not sufficient to streamline, align requirements and improve the efficiency of registration procedures in countries.

The WHO proposes to expedite the registration of IPV and of other vaccines required for emergency use, such as pandemic influenza or Ebola virus vaccines, based on a waiver of the regular marketing authorization procedure in favour of a procedure based on reliance on the producing country NRA approval and/or WHO prequalification. However, the regulatory frameworks in countries are in many cases not sufficiently flexible to accommodate such special circumstances.

Further guidance by WHO on good regulatory practices and best registration practices seem necessary to assist countries to follow defined and transparent procedures to introduce provisions in their regulatory frameworks to allow for flexibilities such as reliance on work performed by other stringent regulators, or reliance on WHO prequalification. WHO is currently developing guidance on good regulatory practices; a second draft for comments is posted on the WHO website (13). Furthermore, work on alignment of country-specific requirements as required in Module 1 of the common technical document seems urgently needed.

Funding: Funding for this work was provided by the Global Polio Eradication Initiative (WHO).

Competing interests: None declared.

\section{Évaluation conjointe des dossiers d'autorisation de mise sur le marché des vaccins antipoliomyélitiques inactivés dans des pays de la Région de la Méditerranée orientale \\ Résumé}

Contexte : En 2012, l'Assemblée mondiale de la Santé a déclaré que l'éradication de la poliomyélite constituait une « urgence programmatique pour la santé publique mondiale ». En réponse à cela, l'Initiative pour l'éradication de la poliomyélite a mis au point le « Plan stratégique pour l'éradication de la poliomyélite et la phase finale 2013-2018 » afin d'éradiquer tous les types de poliomyélite.

Objectif : L'Organisation mondiale de la Santé a invité certains pays de la Région de la Méditerranée orientale à prendre part à une évaluation conjointe des dossiers d'autorisation de mise sur le marché des vaccins antipoliomyélitiques inactivés candidats dans leur formulation simple. Ce processus visait à faciliter les procédures d'évaluation et à accélérer les délais d'enregistrement.

Méthodes : Le présent rapport fait la description de la planification, de l'organisation et de l'exécution de l'évaluation conjointe dans six pays de la Région de la Méditerranée orientale.

Résultats : Les participants ont préparé une liste commune de questions et de préoccupations qui a été distribuée et discutée avec les fabricants respectifs au cours du dernier jour de l'examen. Les fabricants ont répondu aux questions. Les questions auxquelles les fabricants n'ont pas pu apporter de réponses immédiatement ont été traitées après la réunion directement entre les fabricants et les autorités nationales de réglementation. Un rapport final d'évaluation conjointe a été préparé avant la fin de la réunion par les pays participants.

Conclusions : Le rapport se concentre sur les bénéfices de l'exercice et souligne ses lacunes en tant que stratégie unique pour garantir l'enregistrement en temps voulu du vaccin dans les pays cibles. Nous avons également discuté d'autres aspects à traiter de façon à accélérer l'enregistrement effectivement, et par là même l'accès aux vaccins prioritaires. 


\section{تقييم مشترك لملفات تراخيص التسويق الخاصة بلقاحات شلل الأطفال المعطلة في بلدان إقليم شرق المتوسط هدى لنقر، راضية أستاذ علي دهقي، نورا ديليباني

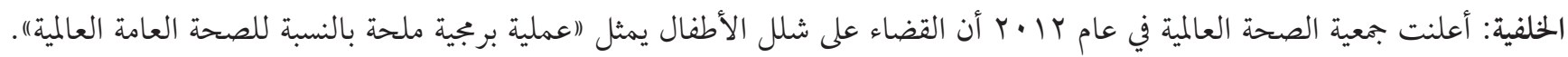

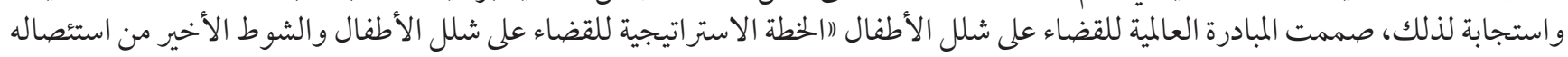

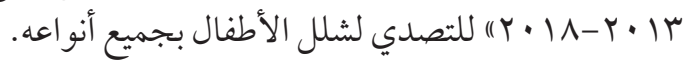

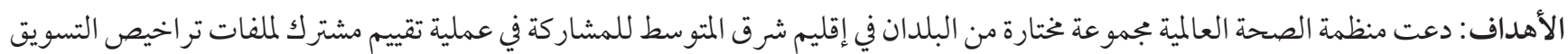

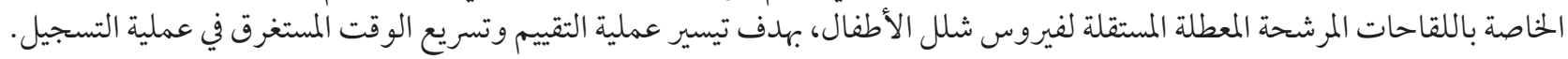

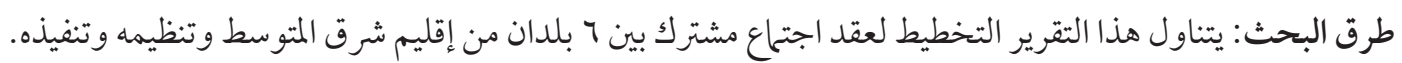

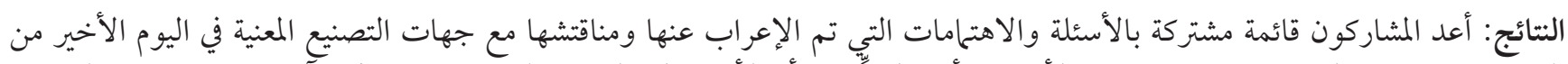

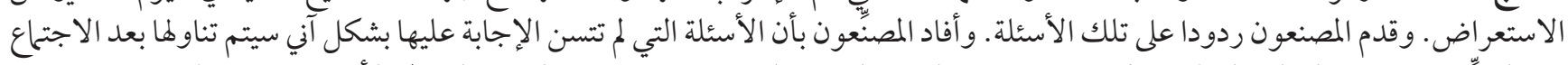

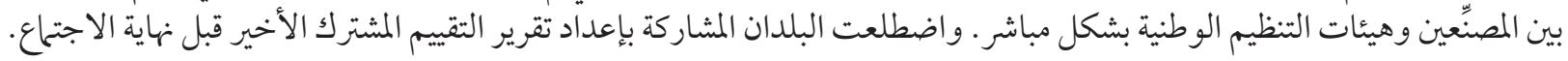

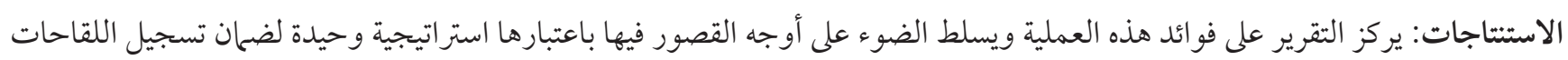

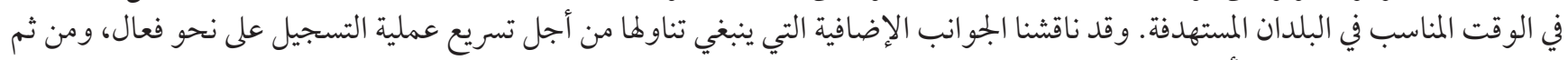
الوصول إلى اللقاحات ذات الأولوية.

\section{References}

1. Global Polio Eradication Initiative. Polio eradication and endgame strategic plan 2013-2018. Geneva: World Health Organization; 2013 (http://www.polioeradication.org/resourcelibrary/strategyandwork.aspx, accessed 21 January 2015).

2. SAGE recommendations. Polio eradication. Geneva: World Health Organization, Weekly Epidemiological Record. 2014;1(89):6-8.

3. Polio vaccines: WHO position paper - March, 2016. Geneva: World Health Organization, Weekly Epidemiological Record, 2016;12(91):145-68.

4. Abdelwahab J, Dietz V, Eggers R, Maher C, Olaniran M, Sandhu H, et al. Strengthening the partnership between routine immunization and the global polio eradication initiative to achieve eradication and assure sustainability. J Infect Dis. 2014;210(Suppl. 1): S498-503. PMID:25316872

5. Expedited procedure for the review of imported prequalified vaccines for use in national immunization programmes. Geneva: World Health Organization; 2007 (WHO/IVB/07/08; http://apps.who.int/iris/bitstream/10665/69686/1/WHO_IVB_07.08_eng.pdf, accessed 21 January 2015).

6. Collaborative procedure between the World Health Organization (WHO) prequalification team and national regulatory authorities in the assessment and accelerated national registration of WHO-prequalified pharmaceutical products and vaccines. Revised draft for comments-ECBS-July 2015. Geneva: World Health Organization; 2015 (http://www.who.int/immunization_standards/vaccine_quality/expedited_review/en/, accessed 26 November 2016).

7. Milstien J, Dellepiane, N, Belgharbi L, Chocarro L, Wood D, Levine MM. Assuring vaccine quality by strengthening regulatory agencies: the work of the World Health Organization. In: Levine MM. New generation of vaccines, 4th ed. New York: Informa Healthcare USA, Inc.; 2010:121-30.

8. Belgharbi L, Dellepiane N, Wood D. Regulation of vaccines in developing countries In: Plotkin SA, Orenstein WA, Offit PA. Vaccines, 6th ed. Philadelphia: Elsevier; 2013:1454-63.

9. A system for the prequalification of vaccines for UN supply. Geneva: World Health Organization; 2012 (http://www.who.int/ immunization_standards/vaccine_quality/pq_system/en/ accessed 22 December 2015).

10. Procedure for assessing the acceptability, in principle, of vaccines for purchase by United Nations Agencies. Geneva: World Health Organization; 2013 (WHO Technical Report Series 978; Annex 6:317-78).

11. Department of Immunization, Vaccines and Biologicals. Assessing the programmatic suitability of vaccine candidates for WHO prequalification (Revision 2014). Geneva: World Health Organization; 2014 (WHO/IVB/14.10; http://apps.who.int/iris/bitstream/10665/148168/1/WHO_IVB_14.10_eng.pdf?ua=1, accessed 21 January 2018).

12. Dellepiane N, Akanmori BD, Gairola S, Jadhav SS, Parker C, Rodriguez C, et al. Regulatory pathways that facilitated timely registration of a new Group A meningococcal conjugate vaccine for Africa's meningitis belt countries. Clin Infect Dis. 2015:61(Suppl. 5): 5428-33. PMID:26553671

13. Good regulatory practices: 5 guidelines for national regulatory authorities for medical 6 products. Draft for comment. Geneva: World Health Organization; 2016 (Working document QAS/16.686; http://www.who.int/medicines/areas/quality_safety/quality_assurance/GoodRegulatory_PracticesPublicConsult.pdf?ua=1, accessed 21 January 2018). 